ARTICLE

https://doi.org/10.1038/s41467-019-13908-6

\title{
Sub-1.4eV bandgap inorganic perovskite solar cells with long-term stability
}

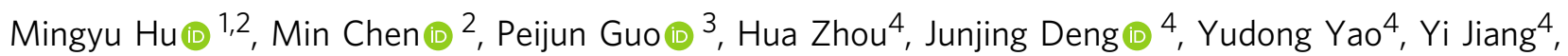
Jue Gong ${ }^{2}$, Zhenghong Dai ${ }^{2}$, Yunxuan Zhou ${ }^{1}$, Feng Qian ${ }^{1}$, Xiaoyu Chong ${ }^{1}$, Jing Feng ${ }^{1 \star}$, Richard D. Schaller (1) ${ }^{3,5}$, Kai Zhu (D) ${ }^{6}$, Nitin P. Padture (i) ${ }^{2 \star} \&$ Yuanyuan Zhou ${ }^{2 \star}$

State-of-the-art halide perovskite solar cells have bandgaps larger than $1.45 \mathrm{eV}$, which restricts their potential for realizing the Shockley-Queisser limit. Previous search for lowbandgap (1.2 to $1.4 \mathrm{eV}$ ) halide perovskites has resulted in several candidates, but all are hybrid organic-inorganic compositions, raising potential concern regarding device stability. Here we show the promise of an inorganic low-bandgap (1.38 eV) $\mathrm{CsPb}_{0.6} \mathrm{Sn}_{0.4} \mathrm{l}_{3}$ perovskite stabilized via interface functionalization. Device efficiency up to $13.37 \%$ is demonstrated. The device shows high operational stability under one-sun-intensity illumination, with $T_{80}$ and $T_{70}$ lifetimes of $653 \mathrm{~h}$ and $1045 \mathrm{~h}$, respectively ( $T_{80}$ and $T_{70}$ represent efficiency decays to $80 \%$ and $70 \%$ of the initial value, respectively), and long-term shelf stability under nitrogen atmosphere. Controlled exposure of the device to ambient atmosphere during a long-term $(1000 \mathrm{~h})$ test does not degrade the efficiency. These findings point to a promising direction for achieving low-bandgap perovskite solar cells with high stability.

\footnotetext{
${ }^{1}$ Faculty of Material Science and Engineering, Kunming University of Science and Technology, Kunming, Yunan 650093, China. ${ }^{2}$ School of Engineering, Brown University, Providence, RI 02912, USA. ${ }^{3}$ Center for Nanoscale Materials, Argonne National Laboratory, Lemont, IL 60439, USA. ${ }^{4}$ Advanced Photon Sources, Argonne National Laboratory, Lemont, IL 60439, USA. ${ }^{5}$ Department of Chemistry, Northwestern University, Evanston, IL 60208, USA. ${ }^{6}$ Chemical and Nanoscience Center, National Renewable Energy Laboratory, Golden, CO 80401, USA. `email: jingfeng@kmust.edu.cn; nitin_padture@brown.edu; yuanyuan_zhou@brown.edu
} 
P erovskite solar cells (PSCs), which employ halide perovskites with the $\mathrm{AMX}_{3}$-structure as light absorbers, have emerged as a potentially disruptive technology in the field of thin-film photovoltaics ${ }^{1-6}$. The power conversion efficiency (PCE) of PSCs has increased rapidly to a certified record of $25.2 \%^{2}$ in the past decade, since the first PSC report by Miyasaka and coworkers in 2009 (ref. ${ }^{7}$ ). While halide perovskites are extremely versatile in composition, the perovskite absorber materials in the state-of-the-art PSCs are generally based on $\mathrm{CH}_{3} \mathrm{NH}_{3} \mathrm{PbI}_{3}\left(\mathrm{MAPbI}_{3}\right)$ and $\mathrm{HC}\left(\mathrm{NH}_{2}\right)_{2} \mathrm{PbI}_{3}\left(\mathrm{FAPbI}_{3}\right)$. Microstructural tailoring of $\mathrm{MAPbI}_{3}$ - and $\mathrm{FAPbI}_{3}$-based perovskite thin films has led to the realization of nearly full potential of $\mathrm{MAPbI}_{3}-$ and $\mathrm{FAPbI}_{3}$-based perovskites as light absorbers, which is a major driving force pushing the technological progress of PSCs ${ }^{1,8}$. Nevertheless, the state-of-the-art perovskites still have bandgaps larger than $1.45 \mathrm{eV}$ (that of pure $\left.\mathrm{FAPbI}_{3}\right)^{9}$. This limits the highest attainable PCE in single-junction devices according to Shockley-Queisser (S-Q) limit, which predicts an ideal bandgap of $1.2-1.4 \mathrm{eV}^{10}$. Thus, there is an unambiguous need to develop perovskites materials with lower (or more ideal) bandgaps. Note that for the ease of description and comparison, we treat all perovskite materials that exhibit bandgaps lower than pure $\mathrm{FAPbI}_{3}(1.45 \mathrm{eV})$ in the category of low-bandgap perovskites.

There have been several reports in the literature in this important direction of perovskites research, demonstrating the feasibility of compositions such as $\left(\mathrm{FAPbI}_{3}\right)_{0.7}\left(\mathrm{CsSnI}_{3}\right)_{0.3}$ (ref. $\left.{ }^{11}\right)$, $\left(\mathrm{FASnI}_{3}\right)_{0.6}\left(\mathrm{MAPbI}_{3}\right)_{0.4} \quad$ (refs. $\left.{ }^{12,13}\right), \quad\left(\mathrm{FASnI}_{3}\right)_{0.6}\left(\mathrm{MAPbI}_{3}\right)_{0.34}$ $\left(\mathrm{MAPbBr}_{3}\right)_{0.06}$ (ref. $\left.{ }^{14}\right), \mathrm{FAPb}_{0.5} \mathrm{Sn}_{0.5} \mathrm{I}_{3} \quad$ (ref. ${ }^{15}$ ), and $\mathrm{MAPb}_{0.5} \mathrm{Sn}_{0.5} \mathrm{I}_{3}$ (ref. ${ }^{16}$ ) for PSCs. Low-bandgap PSCs with PCE as high as $20.5 \%$ and $21.1 \%$ have been recently demonstrated by Tong et al. ${ }^{17}$, using an additive-mediated crystallization process, and by Lin et al. ${ }^{18}$, using a so-called 'comproportionation' approach. It is clear that continued improvements in the processing and microstructural engineering of low-bandgap perovskite thin films will further boost the PCE, which may eventually surpass the PCEs of the state-of-the-art PSCs. However, all the reported high-performance low-bandgap perovskites invariably contain a significant portion of organic component $\left(\mathrm{MA}^{+}\right.$or $\mathrm{FA}^{+}$) occupying the A-sites in the $\mathrm{AMX}_{3}$ perovskite structure, where $\mathrm{M}$ is $\mathrm{Pb}^{2+}$ or/and $\mathrm{Sn}^{2+}$ and $\mathrm{X}$ is a halide anion. The A-site organic cations, especially $\mathrm{MA}^{+}$, are often associated with high hygroscopicity and low thermal stability ${ }^{19,20}$, raising significant concerns regarding their long-term stability. To date, the best reported stability in low-bandgap PSCs shows a modest $T_{80}$ device-operation lifetime of $222 \mathrm{~h}^{17}$.

In this work, we demonstrate the use of an inorganic perovskite composition of $\mathrm{CsPb}_{0.6} \mathrm{Sn}_{0.4} \mathrm{I}_{3}$ with a low bandgap of $1.38 \mathrm{eV}$ for PSCs. The inorganic nature renders this perovskite inherently more stable than its hybrid organic-inorganic counterparts. Importantly, it is shown that a rational strategy of interface functionalization further stabilizes the $\mathrm{CsPb}_{0.6} \mathrm{Sn}_{0.4} \mathrm{I}_{3}$ perovskite thin films and passivates the defects, making $\mathrm{CsPb}_{0.6} \mathrm{Sn}_{0.4} \mathrm{I}_{3}$ perovskite a promising candidate for use in low-bandgap PSCs. High-PCE PSC devices are achieved with promising long-term operational and shelf stabilities.

\section{Results}

Synthesis and properties of $\mathrm{CsPb}_{0.6} \mathrm{Sn}_{0.4} I_{3}$ perovskites. The $\mathrm{CsPb}_{0.6} \mathrm{Sn}_{0.4} \mathrm{I}_{3}$ perovskite is a solid-solution alloy phase (shown schematically in Fig. 1a) of $\mathrm{CsPbI}_{3}$ and $\mathrm{CsSnI}_{3}$, which is synthesized using the 'one-step' solution-processing approach (see details in Methods). The X-ray diffraction (XRD) pattern of assynthesized $\mathrm{CsPb}_{0.6} \mathrm{Sn}_{0.4} \mathrm{I}_{3}$ thin films is shown in Fig. 1b. Rietveld refinement suggests a tetragonal $\beta$ phase, with space group $P 4 /$ $m b m$ (lattice parameters: $a=b=8.78 \AA ; c=6.31 \AA$ ), at room temperature (RT). In Supplementary Fig. 1, the UV-vis absorption spectrum of a $\mathrm{CsPb}_{0.6} \mathrm{Sn}_{0.4} \mathrm{I}_{3}$ perovskite thin film shows fullrange of light absorption from the UV to near-infrared regions. The Tauc plot in Fig. 1c indicates that $\mathrm{CsPb}_{0.6} \mathrm{Sn}_{0.4} \mathrm{I}_{3}$ perovskite exhibits a bandgap of $1.38 \mathrm{eV}$. For comparison, the bandgap of the $\mathrm{CsPbI}_{3}$ perovskite is $1.73 \mathrm{eV}^{21-23}$. The variation of experimental bandgaps as a function of $x$ in $\mathrm{CsPb}_{1-x} \mathrm{Sn}_{x} \mathrm{I}_{3}$ has been further studied, which shows a decreasing bandgap with increasing $x$, as shown in Fig. 1d. This is in good agreement with the results from density functional theory (DFT) calculations. However, the bandgap 'bowing' effect ${ }^{24}$, which is typically observed in hybrid $\mathrm{Pb}-\mathrm{Sn}$ alloy perovskites, is not observed in our inorganic $\mathrm{CsPb}_{1-x} \mathrm{Sn}_{x} \mathrm{I}_{3}$, which could be related to the absence of organic cations. The projected density of states (DOS) profile of $\mathrm{CsPb}_{1-x} \mathrm{Sn}_{x} \mathrm{I}_{3}$ alloy $(x=0.5)$ is presented in Fig. 1e, together with the experimental ultraviolet photoelectron spectrum (UPS), which captures the overall valence-band states. Here, the substitution of $\mathrm{Pb}^{2+}$ by $\mathrm{Sn}^{2+}$ in the $\mathrm{AMX}_{3}$ structure narrows the bandgap by pushing the valence band maximum (VBM) up, as $\mathrm{Sn}^{2+}$ cations exhibit higher-energy occupied $s^{2}$ orbitals that couple with I $p$ orbitals ${ }^{9}$. Interestingly, the experimentally measured change in the bandgap $\left(E_{\mathrm{g}}\right)$ with $x$ does not strictly follow the Vegard's law (linear relationship) in $\mathrm{CsPb}_{1-x} \mathrm{Sn}_{x} \mathrm{I}_{3}$. Instead, an empirical biexponential function is needed to fit the descending trend, leading to an initially steep decrease in the bandgap when only small amount of $\mathrm{Sn}^{2+}$ is incorporated. This offers the opportunity for achieving the desired low bandgaps in $\mathrm{CsPb}_{1-x} \mathrm{Sn}_{x} \mathrm{I}_{3}$ perovskites with a relatively small value of $x=0.4$. Note that a relatively low content of $\mathrm{Sn}^{2+}$ makes the manipulation of material properties much easier because the concentration of undesirable Sn-related defects, which are dominant in Sn-containing halide perovskites ${ }^{25}$, is expected to be lower. In this context, preliminary device effort (Supplementary Fig. 2) suggests that it is more challenging to make higher-Sn-content $\mathrm{CsPb}_{1-x} \mathrm{Sn}_{x} \mathrm{I}_{3}$-based PSCs even if they offer the prospect of lowering the bandgap. Thus, the $\mathrm{CsPb}_{0.6} \mathrm{Sn}_{0.4} \mathrm{I}_{3}$ composition appears optimum as it combines the merits of good structural stability and the stability of the $\mathrm{Sn}^{2+}$ cations.

The low-bandgap $\mathrm{CsPb}_{0.6} \mathrm{Sn}_{0.4} \mathrm{I}_{3}$ perovskite could be advantageous over their hybrid organic-inorganic counterparts in terms of easier solution-processing and higher intrinsic structural stability. Supplementary Fig. 3 shows that the one-step spincoating method can be used without any antisolvent treatment to deposit uniform $\mathrm{CsPb}_{0.6} \mathrm{Sn}_{0.4} \mathrm{I}_{3}$ perovskite thin films. In contrast, their hybrid counterparts show poor film coverage in the absence of additional antisolvent treatment. $\mathrm{CsPb}_{0.6} \mathrm{Sn}_{0.4} \mathrm{I}_{3}$ perovskite exhibits improved phase stability compared to the widely studied $\mathrm{CsPbI}_{3}$ perovskite. As seen in Supplementary Fig. 4, the $\mathrm{CsPb}_{0.6} \mathrm{Sn}_{0.4} \mathrm{I}_{3}$ perovskite thin film remains black (indication of the perovskite phase retention) upon heating at $80^{\circ} \mathrm{C}$ for up to $18 \mathrm{~min}$ in a nitrogen-filled glovebox, whereas the $\mathrm{CsPbI}_{3}$ perovskite thin film turns yellow quickly. This appears to be related to the Goldschmidt tolerance factor, which determines the stability of the perovskite structure: $t=\frac{r_{\mathrm{A}}+r_{\mathrm{X}}}{\sqrt{2}\left(r_{\mathrm{M}}+r_{\mathrm{X}}\right)} 26$, where $r_{\mathrm{A}}, r_{\mathrm{M}}$, and $r_{\mathrm{X}}$ are radii of $\mathrm{A}, \mathrm{M}$, and $\mathrm{X}$ cations, respectively, in the $\mathrm{AMX}_{3}$ perovskite structure. Partial substitution of $\mathrm{Pb}$ with smaller $\mathrm{Sn}$ cation may result in a more ideal $t$ value, which resembles the case of $\mathrm{CsSn}_{0.5} \mathrm{Ge}_{0.5} \mathrm{I}_{3}$ perovskite reported by us earlier ${ }^{27}$. We have further calculated the formation energy of $\mathrm{CsPb}_{1-x} \mathrm{Sn}_{x} \mathrm{I}_{3}$ (Supplementary Fig. 5), which shows a thermodynamically more stable crystal structure with $\mathrm{Sn}^{2+}$ substitution. The phase stability could also be related to its unique crystal symmetry (tetragonal $\beta$ phase $)^{28}$. However, $\mathrm{CsPb}_{0.6} \mathrm{Sn}_{0.4} \mathrm{I}_{3}$ perovskite is still not sufficiently stable under environmental conditions. When a neat $\mathrm{CsPb}_{0.6} \mathrm{Sn}_{0.4} \mathrm{I}_{3}$ perovskite thin film is exposed to ambient 
a

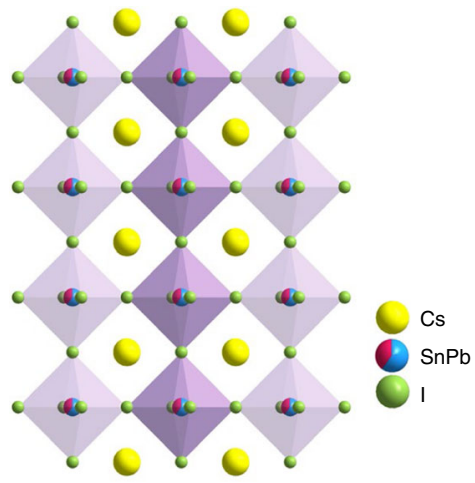

C

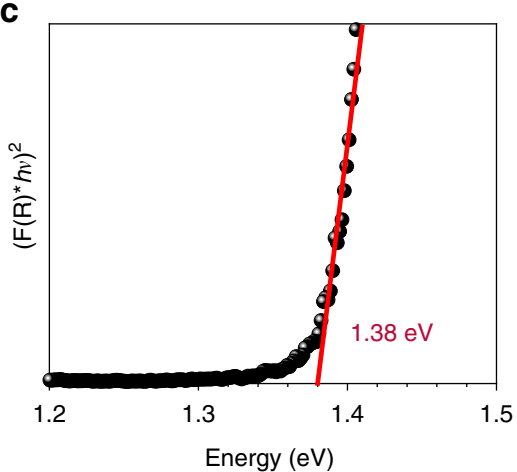

b

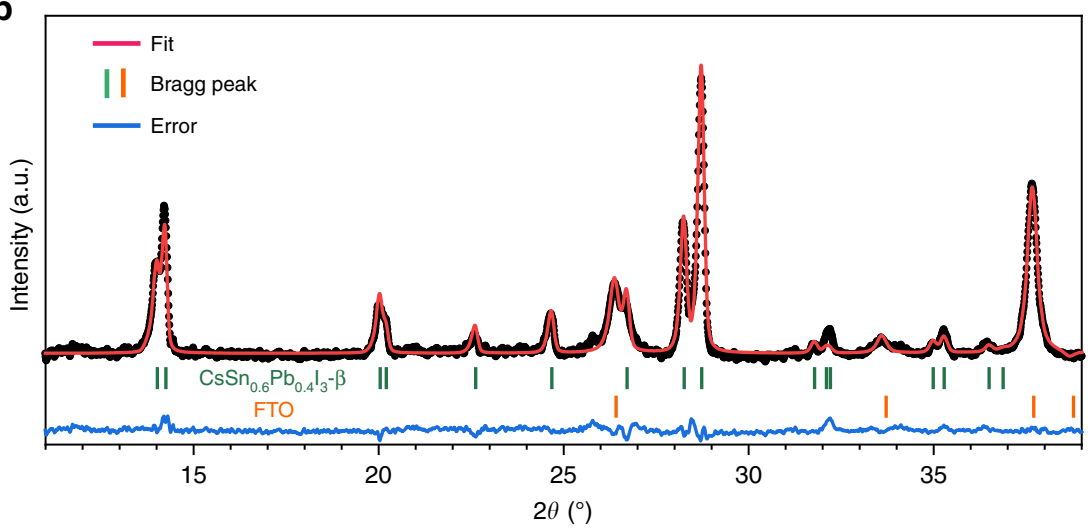

d

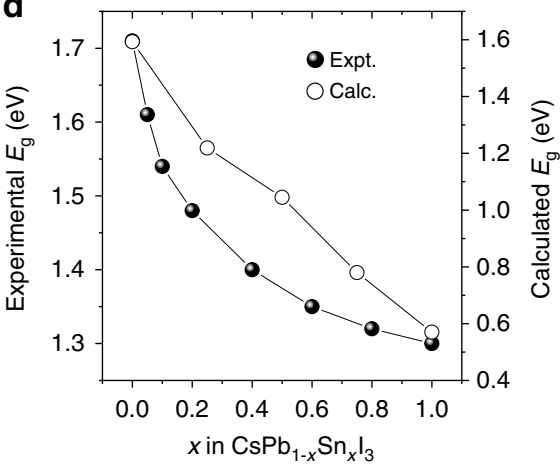

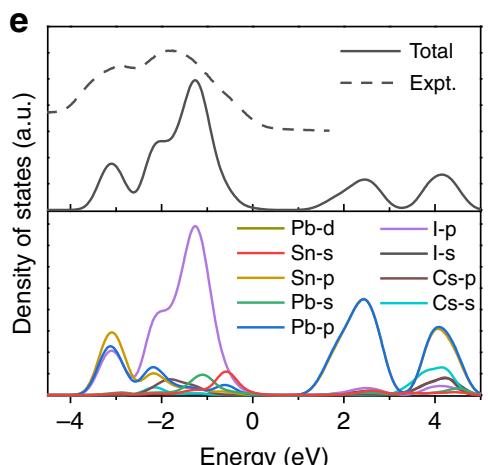

Fig. 1 Synthesis and optical properties of $\mathbf{C s P b _ { 0 . 6 }} \mathbf{S n}_{\mathbf{0 . 4}} \mathbf{l}_{\mathbf{3}}$ perovskites. a Schematic crystal structure of $\mathrm{CsPb}_{1-x} \mathrm{Sn}_{x} \mathrm{I}_{3} . \mathbf{b} \times \mathrm{XRD}$ pattern of $\mathrm{CsPb}_{0.6} \mathrm{Sn}_{0.4} \mathrm{l}_{3}$ perovskite thin film and its Rietveld refinement. c Tauc plot of $\mathrm{CsPb}_{0.6} \mathrm{Sn}_{0.4} \mathrm{l}_{3}$ perovskite thin film. $\mathbf{d}$ Variation of experimental (solid circle) and calculated (open circle) bandgaps as a function of $x$ in $\left.\mathrm{CsPb}_{1-x} \mathrm{Sn}_{x}\right|_{3}$. e DOS of a typical $\mathrm{CsPb}_{1-x} \mathrm{Sn}_{x} \mathrm{I}_{3}(x=0.5)$ perovskite calculated using DFT. Dashed curve is experimental UPS spectrum.

condition in air with high relative humidity (RT; $80 \% \mathrm{RH}$ ), it turns yellow quickly (Supplementary Fig. 6). To mitigate this environmental degradation issue, an interface-functionalization approach is employed, as described below.

Interface-functionalization of $\mathrm{CsPb}_{0.6} \mathrm{Sn}_{0.4} \mathrm{I}_{3}$ perovskites. To further enhance the stability of $\mathrm{CsPb}_{0.6} \mathrm{Sn}_{0.4} \mathrm{I}_{3}$ perovskite thin films, chemical functionalization of interfaces is performed using a combination of two previously reported approaches. The first approach is the functionalization of grain boundaries by incorporating $\mathrm{SnF}_{2} \cdot 3 \mathrm{FACl}$ additive in the solution processing of $\mathrm{CsPb}_{0.6} \mathrm{Sn}_{0.4} \mathrm{I}_{3}$ perovskite thin films. This is expected to result in the continuous decoration of grain boundaries with anti-oxidating $\mathrm{SnF}_{2}$ phases. The merit of $\mathrm{SnF}_{2} \bullet 3 \mathrm{FACl}$ over pure $\mathrm{SnF}_{2}$ is that it not only provides uniform grain boundary coating via the $\mathrm{SnF}_{2} \cdot 3 \mathrm{FACl}$-to- $\mathrm{SnF}_{2}$ decomposition process, but also reduces grain-boundary density (larger average grain size) significantly, which was demonstrated by us previously ${ }^{11}$. The second approach is functionalization of surfaces, which entails spin-coating of an organic salt, (aminomethyl) piperidinium diiodide (4AMP) $\mathrm{I}_{2}$, on the top surface of the grainboundary functionalized $\mathrm{CsPb}_{0.6} \mathrm{Sn}_{0.4} \mathrm{I}_{3}$ perovskite thin film. The large organic-molecule (4AMP) ${ }^{2+}$ cations are expected to not only passivate the surface defects but also form a hydrophobic encapsulation layer ${ }^{29-31}$. Thus, the simultaneous functionalization of all interfaces in thin films (see Fig. 2) is expected to protect $\mathrm{CsPb}_{0.6} \mathrm{Sn}_{0.4} \mathrm{I}_{3}$ perovskite grains at the nanoscale, mitigating the environmental degradation significantly ${ }^{32}$. In the following discussion, the low-bandgap $\mathrm{CsPb}_{0.6} \mathrm{Sn}_{0.4} \mathrm{I}_{3}$ perovskites made without any functionalization, with only grain-boundary functionalization, and with both grain-boundary and surface functionalization are denoted as $\quad \mathrm{N}-\mathrm{CsPb}_{0.6} \mathrm{Sn}_{0.4} \mathrm{I}_{3}, \quad \mathrm{G}-\mathrm{CsPb}_{0.6} \mathrm{Sn}_{0.4} \mathrm{I}_{3}$, and $\mathrm{G}-\mathrm{S}-\mathrm{CsPb}_{0.6} \mathrm{Sn}_{0.4} \mathrm{I}_{3}$, respectively.

Figure $3 \mathrm{a}, \mathrm{b}$ shows top-view scanning electron microscopy (SEM) images of $\mathrm{N}-\mathrm{CsPb}_{0.6} \mathrm{Sn}_{0.4} \mathrm{I}_{3}$ and $\mathrm{G}-\mathrm{CsPb}_{0.6} \mathrm{Sn}_{0.4} \mathrm{I}_{3}$ perovskite thin films. The addition of $\mathrm{SnF}_{2} \cdot 3 \mathrm{FACl}$ increases the average grain size from 120 to $180 \mathrm{~nm}$, as measured using image analyses (Supplementary Fig. 7). The XRD patterns in Fig. 3e indicate enhanced crystallinity and (110) texture in the G$\mathrm{CsPb}_{0.6} \mathrm{Sn}_{0.4} \mathrm{I}_{3}$ thin film. This correspondingly increases light absorption, as shown in the UV-vis spectra (Fig. 3d). The enhancement of the microstructure and the optical properties can be attributed to two factors: (i) FACl component reduces grain-boundary density and (ii) the remaining $\mathrm{SnF}_{2}$ helps reduce $S n$-defects within the grains in situ ${ }^{11}$. The SEM image and XRD pattern of a G-S-CsPb ${ }_{0.6} \mathrm{Sn}_{0.4} \mathrm{I}_{3}$ perovskite thin film are shown in Fig. $3 c$, e. A sequential (4AMP) $\mathrm{I}_{2}$ treatment does not result in an obvious effect on the overall morphology and film crystallinity, which is as expected. There is also no apparent change in the absorption characteristics of the thin film (Fig. 3d). We further analyzed the detailed microstructure and chemical composition in the G-S-CsPb ${ }_{0.6} \mathrm{Sn}_{0.4} \mathrm{I}_{3}$ thin film using X-ray ptychography and X-ray photoelectron spectroscopy (XPS). X-ray ptychography is a coherence-based X-ray technique that combines the power of scanning X-ray microscopy with coherent diffractive imaging. This allows for the multidimensional rendering of internal states (e.g. microstructure and morphology) of complex materials by utilizing both absorption and phase contrast for visualization ${ }^{33}$. Figure $3 \mathrm{f}$, g shows two-dimensional transmission-mode X-ray ptychography reconstructed images of a $\mathrm{G}-\mathrm{CsPb} \mathrm{B}_{0.6} \mathrm{Sn}_{0.4} \mathrm{I}_{3}$ 


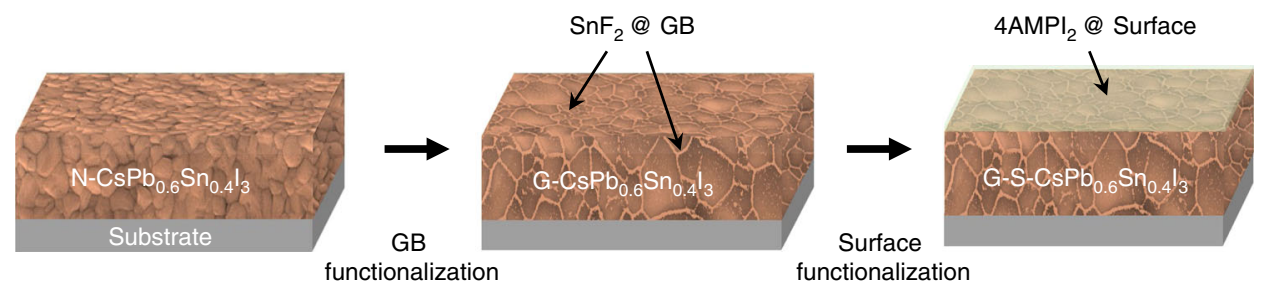

Fig. 2 Stabilization approach for $\mathbf{C s P b}_{\mathbf{0 . 6}} \mathbf{S n}_{\mathbf{0 . 4}} \mathbf{l}_{\mathbf{3}}$ perovskites. Schematic illustration of interface functionalization of $\mathrm{CsPb}_{0.6} \mathrm{Sn}_{0.4} \mathrm{l}_{3}$ perovskite thin films via two steps: (i) grain-boundary (GB) functionalization with continuous $\mathrm{SnF}_{2}$ (derived from $\mathrm{SnF}_{2} \bullet 3 \mathrm{FACl}$ ) and (ii) additional top-surface functionalization with $\left.(4 \mathrm{AMP})\right|_{2}$ salt.
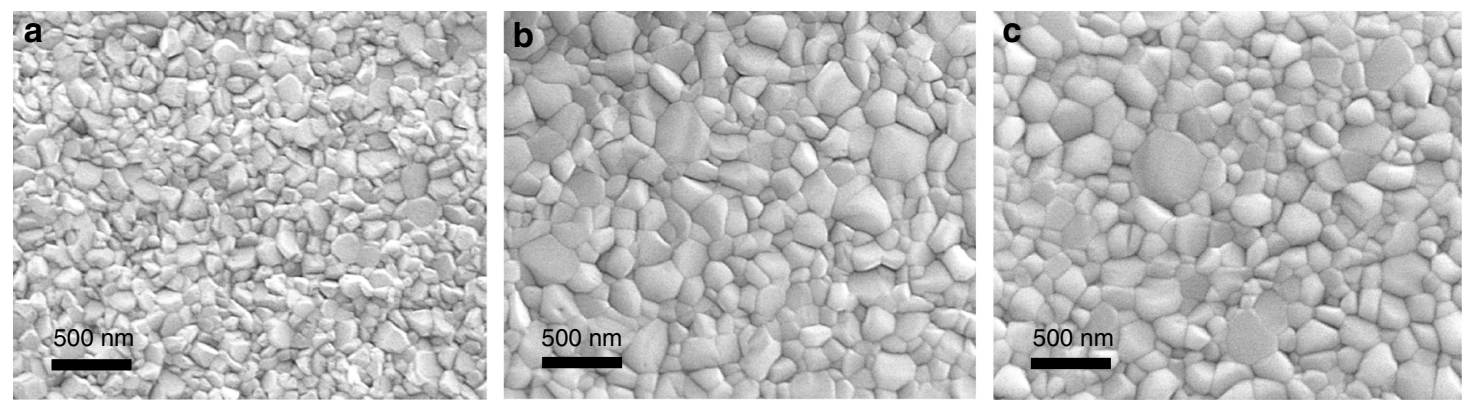

d
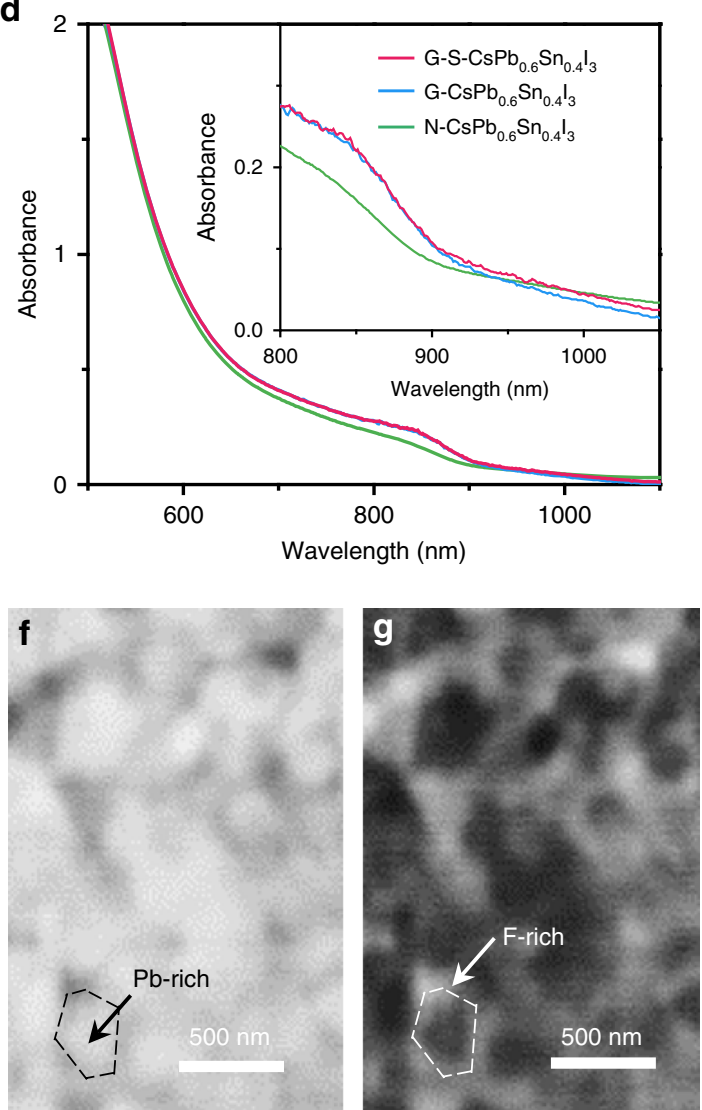
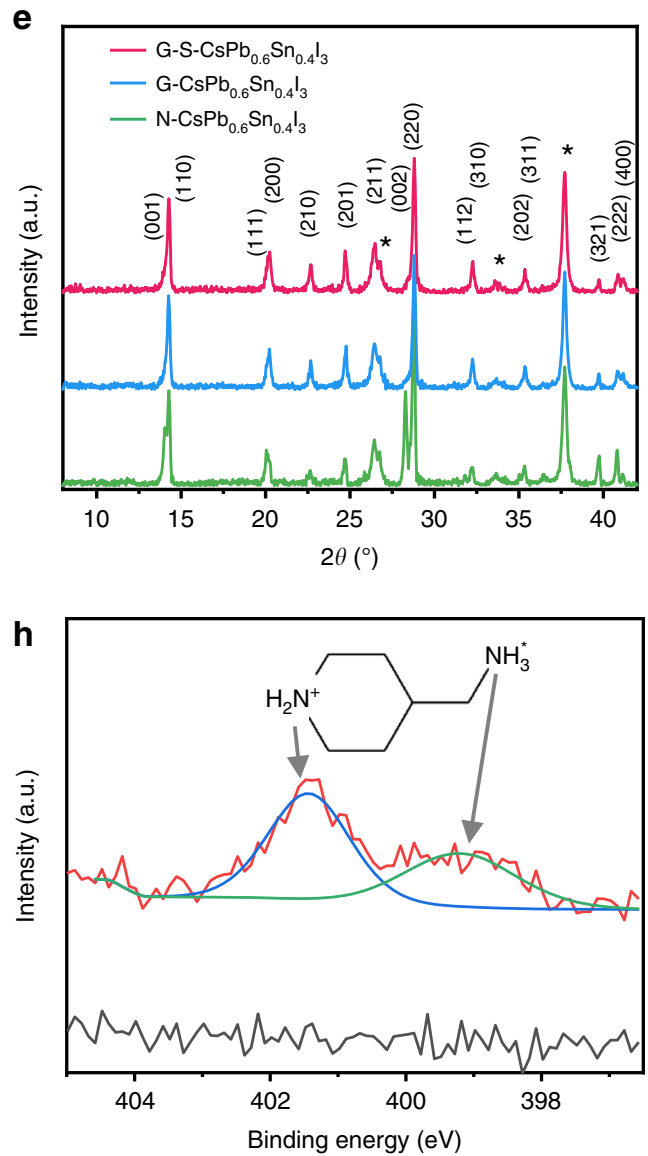

Fig. 3 Characterizations of $\mathbf{C s P b}_{\mathbf{0 . 6}} \mathbf{S n}_{\mathbf{0 . 4}} \mathbf{I}_{\mathbf{3}}$ perovskites. SEM micrographs of $\left.\mathrm{CsPb}_{0.6} \mathrm{Sn}_{0.4}\right|_{3}$ thin films: a N-CsPb $\left.{ }_{0.6} \mathrm{Sn}_{0.4}\right|_{3}, \mathbf{b}$ G-CsPb $b_{0.6} \mathrm{Sn}_{0.4} \mathrm{I}_{3}$, and $\mathbf{c}$ G-S$\mathrm{CsPb}_{0.6} \mathrm{Sn}_{0.4} \mathrm{I}_{3}$. $\mathbf{d}$ UV-vis absorption spectra of $\mathrm{N}-\mathrm{CsPb}_{0.6} \mathrm{Sn}_{0.4} \mathrm{I}_{3}, \mathrm{G}-\mathrm{CsPb}_{0.6} \mathrm{Sn}_{0.4} \mathrm{I}_{3}$, and $\mathrm{G}-\mathrm{S}-\mathrm{CsPb}_{0.6} \mathrm{Sn}_{0.4} \mathrm{I}_{3}$ thin films. e XRD patterns of $\mathrm{N}-\mathrm{Cs}_{\mathrm{P}} \mathrm{Pb}{ }_{0.6} \mathrm{Sn}_{0.4} \mathrm{I}_{3}$, $\mathrm{G}-\mathrm{CsPb}_{0.6} \mathrm{Sn}_{0.4} \mathrm{I}_{3}$, and $\mathrm{G}-\mathrm{S}-\mathrm{CsPb}_{0.6} \mathrm{Sn}_{0.4} \mathrm{l}_{3}$ thin films. The FTO substrate XRD peak marked by '*'. X-ray ptychography reconstructed-image of the G$\mathrm{CsPb}_{0.6} \mathrm{Sn}_{0.4} \mathrm{l}_{3}$ thin film. $\mathbf{f}$ Phase-contrast inverted grain distribution and $\mathbf{g}$ phase-contrast enhanced grain-boundary regions. $\mathbf{h}$ XPS spectra of $\mathrm{CsPb}_{0.6} \mathrm{Sn}_{0.4} \mathrm{l}_{3}$ perovskite thin films with and without (4AMP) $\mathrm{I}_{2}$ surface treatment. 
perovskite thin film, where two regions with clearly distinct contrasts are observed. Heavy-element $(\mathrm{Pb})$ and light-element (F) rich phases are discernable at grain and grain-boundary regions, respectively. In Figure $3 \mathrm{~h}$, the $\mathrm{N} 1 s$ core-level XPS spectrum of the $\mathrm{CsPb}_{0.6} \mathrm{Sn}_{0.4} \mathrm{I}_{3}$ perovskite thin film with $(4 \mathrm{AMP}) \mathrm{I}_{2}$ surface treatment is shown, where two $\mathrm{N} 1$ s peaks are observed at 399.20 and $401.43 \mathrm{eV}$ that are respectively assigned to $-\mathrm{NH}_{3}$ and $-\mathrm{NH}_{2}{ }^{34}$. This confirms the formation of a thin layer of organic (4AMP) ${ }^{2+}$ cations on the top surface of G-S-CsPb ${ }_{0.6} \mathrm{Sn}_{0.4} \mathrm{I}_{3}$ perovskite thin films. More careful analyses in Supplementary Figs. 8-10 show no obvious traces of incorporation of $\mathrm{FA}^{+}, \mathrm{Cl}^{-}$, or $(4 \mathrm{AMP})^{2+}$ within the perovskite lattice, which attests to the all-inorganic nature of the G-S-CsPb ${ }_{0.6} \mathrm{Sn}_{0.4} \mathrm{I}_{3}$ thin films.

Properties and stability of $\mathrm{CsPb}_{\mathbf{0 . 6}} \mathbf{S n}_{\mathbf{0 . 4}} \mathrm{I}_{\mathbf{3}}$ perovskites. Figure $4 \mathrm{a}$ shows the transient absorption (TA) kinetics of $\mathrm{N}-\mathrm{CsPb}_{0.6} \mathrm{Sn}_{0.4} \mathrm{I}_{3}$, G-CsPb $b_{0.6} \mathrm{Sn}_{0.4} \mathrm{I}_{3}$, and G-S-CsPb $\mathrm{C}_{0.6} \mathrm{Sn}_{0.4} \mathrm{I}_{3}$ thin films. The kinetics were fitted using empirical biexponential functions with two time-constants $\tau_{1}$ and $\tau_{2}$ (see Supplementary Table 1 for fitting parameters), which could be related to surface and bulk recombination rates, respectively. Transient photoluminescence (TRPL) decay kinetics were also acquired, again showing an increase in the PL lifetimes with grain-boundary and surface functionalization. In order to estimate the overall trap densities, dark current-voltage $(I-V)$ curves of capacitor-like devices were measured using $\mathrm{N}-\mathrm{CsPb}_{0.6} \mathrm{Sn}_{0.4} \mathrm{I}_{3}, \mathrm{G}-\mathrm{CsPb}_{0.6} \mathrm{Sn}_{0.4} \mathrm{I}_{3}$, and G-S$\mathrm{CsPb}_{0.6} \mathrm{Sn}_{0.4} \mathrm{I}_{3}$ thin films. The capacitor-like device architecture is shown schematically in Supplementary Fig. 11. The trap-filled limited voltages $\left(V_{\mathrm{TFL}}\right)$ were determined from the $I-V$ curves, showing $1.11 \mathrm{~V}, 0.61 \mathrm{~V}$, and $0.34 \mathrm{~V}$ for $\mathrm{N}-\mathrm{CsPb}_{0.6} \mathrm{Sn}_{0.4} \mathrm{I}_{3}$. G$\mathrm{CsPb}_{0.6} \mathrm{Sn}_{0.4} \mathrm{I}_{3}$, and $\mathrm{G}-\mathrm{S}-\mathrm{CsPb}_{0.6} \mathrm{Sn}_{0.4} \mathrm{I}_{3}$, respectively (Fig. $4 \mathrm{~b}$ ). The trap densities, $n_{\text {trap }}$, are estimated using the equation: $n_{\text {trap }}=\frac{2 \varepsilon_{0} \varepsilon_{r} V_{\text {TFL }}}{e d^{2}}$, where $e$ is the elementary charge, $d$ the film thickness, $\varepsilon_{\mathrm{r}}$ the relative dielectric constant, and $\varepsilon_{0}$ the vacuum permittivity. Thus, the estimated trap densities for $\mathrm{N}$ $\mathrm{CsPb}_{0.6} \mathrm{Sn}_{0.4} \mathrm{I}_{3}, \quad \mathrm{G}-\mathrm{CsPb}_{0.6} \mathrm{Sn}_{0.4} \mathrm{I}_{3}$, and G-S-CsPb $\mathrm{C}_{0.6} \mathrm{Sn}_{0.4} \mathrm{I}_{3}$ are $5.50 \times 10^{16}, 3.02 \times 10^{16}$, and $1.68 \times 10^{16} \mathrm{~cm}^{-3}$, respectively. These a

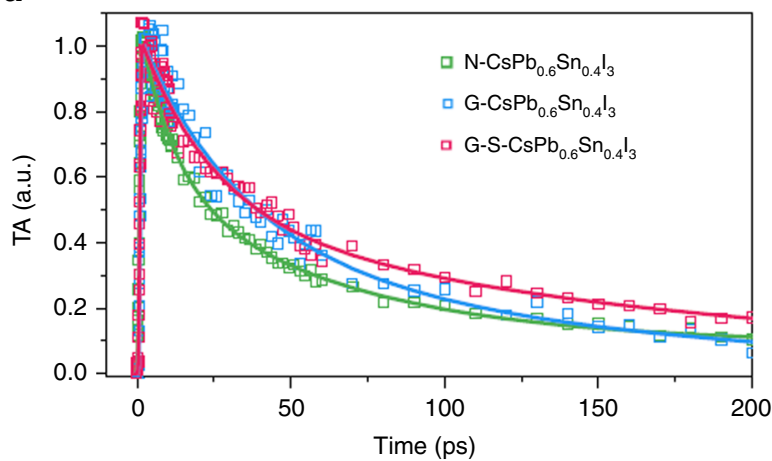

b
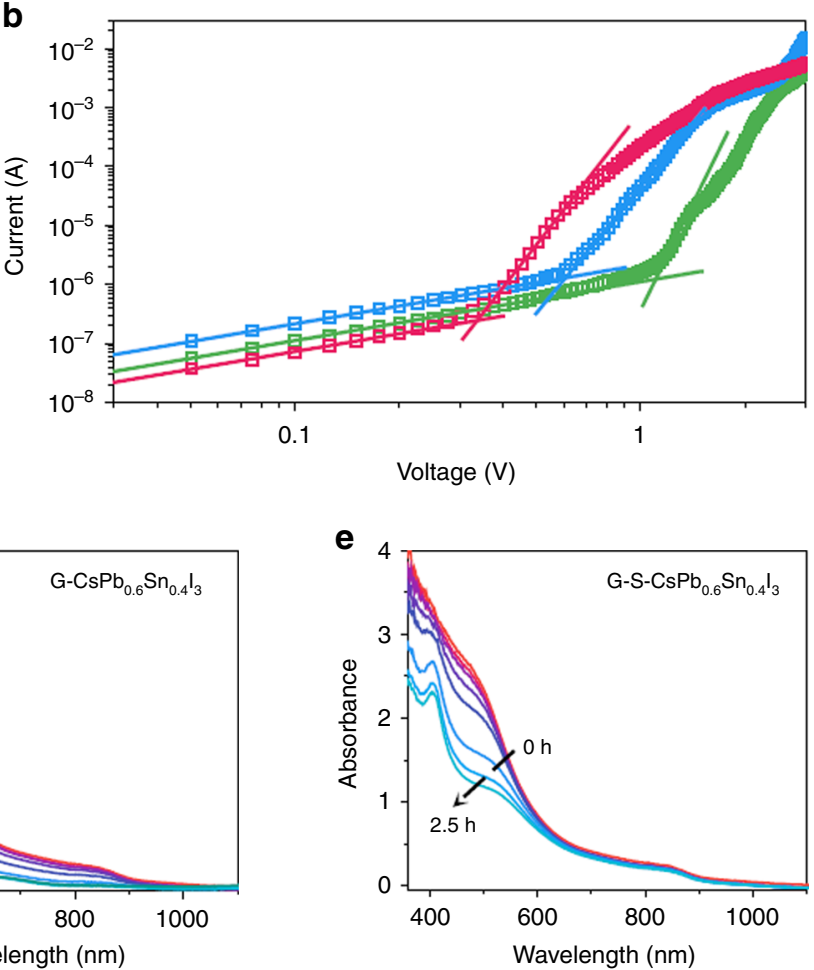

Wavelength $(\mathrm{nm})$
C

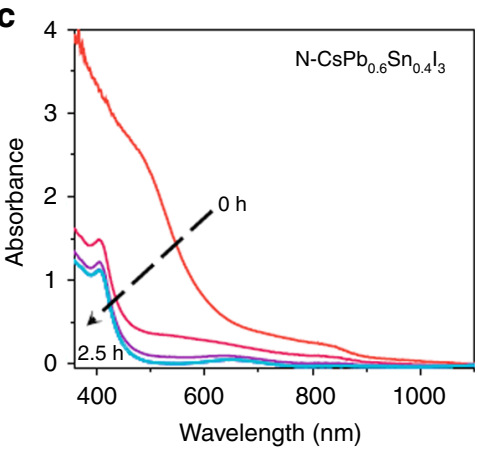

d

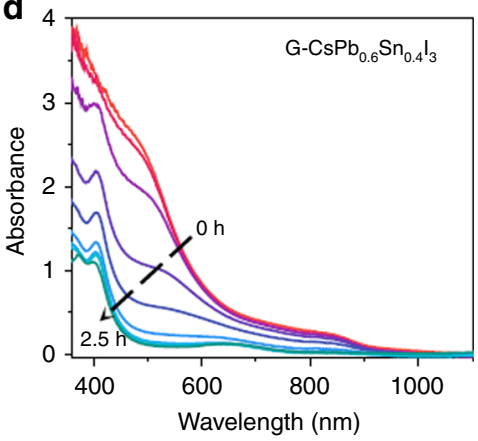

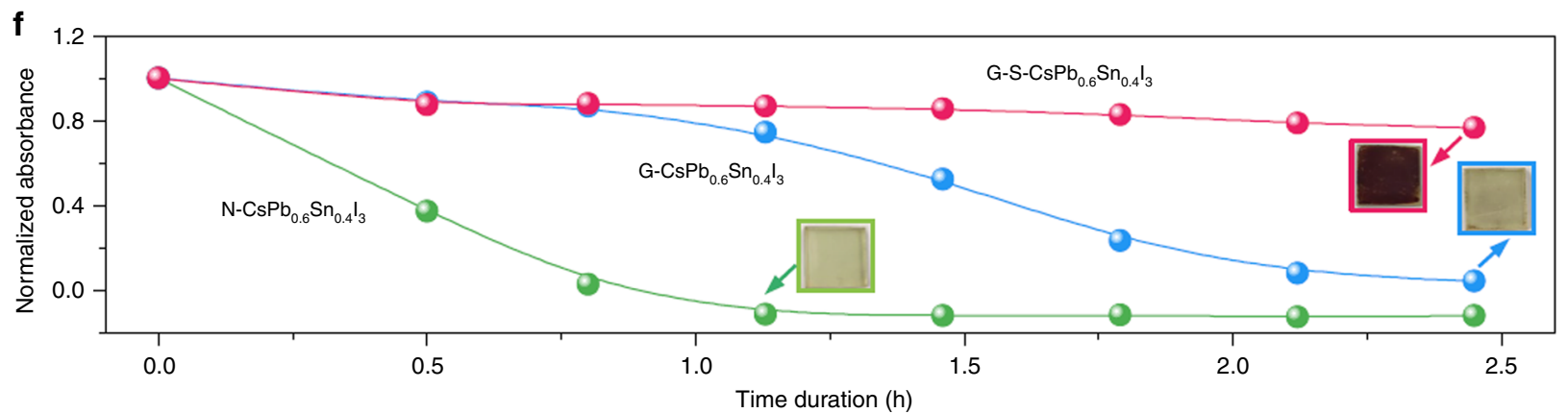

Fig. 4 Physical properties and chemical stability of $\mathbf{C s P b}_{\mathbf{0}} \mathbf{0}_{\mathbf{6}} \mathbf{S n}_{\mathbf{0 . 4}} \mathbf{l}_{\mathbf{3}}$ perovskites. a TA spectra of N-CsPb $\left.{ }_{0.6} \mathrm{Sn}_{0.4}\right|_{3}, \mathrm{G}-\mathrm{CsPb}_{0.6} \mathrm{Sn}_{0.4} \mathrm{l}_{3}$, and G-S$\mathrm{CsPb}_{0.6} \mathrm{Sn}_{0.4} \mathrm{I}_{3}$ thin films. b Dark current-voltage curves of capacitor-like devices using N-CsPb${ }_{0.6} \mathrm{Sn}_{0.4} \mathrm{I}_{3}, \mathrm{G}-\mathrm{CsPb}_{0.6} \mathrm{Sn}_{0.4} \mathrm{I}_{3}$, and G-S-CsPb $\mathrm{C}_{0.6} \mathrm{Sn}_{0.4} \mathrm{I}_{3} \mathrm{thin}$ films. UV-vis spectra evolution of thin films stored controlled ambient conditions (RT, 80\% RH). c N-CsPb $\left.{ }_{0.6} \mathrm{Sn}_{0.4}\right|_{3}, \mathbf{d} \mathrm{G}-\mathrm{CsPb}_{0.6} \mathrm{Sn}_{0.4} \mathrm{l}_{3}$, and e G-S$\mathrm{CsPb}_{0.6} \mathrm{Sn}_{0.4} \mathrm{l}_{3}$ thin films. f Absorbance (at $800 \mathrm{~nm}$ ) variation as a function of storage duration. Insets are corresponding photographs of the thin films. 
results further confirm the beneficial effects of grain-boundary and surface passivation.

The evolution of UV-vis spectra of $\mathrm{N}-\mathrm{CsPb}_{0.6} \mathrm{Sn}_{0.4} \mathrm{I}_{3}, \mathrm{G}$ $\mathrm{CsPb}_{0.6} \mathrm{Sn}_{0.4} \mathrm{I}_{3}$, and G-S-CsPb $\mathrm{C}_{0.6} \mathrm{Sn}_{0.4} \mathrm{I}_{3}$ thin films was measured as a function of storage duration under controlled ambient conditions (RT, 80\% RH), and are shown in Fig. 4c-e. The absorption of $\mathrm{N}-\mathrm{CsPb}_{0.6} \mathrm{Sn}_{0.4} \mathrm{I}_{3}$ thin film decreases very rapidly upon ambient exposure. After $2.5 \mathrm{~h}$, the film is completely bleached, which is due to the degradation of the $\mathrm{CsPb}_{0.6} \mathrm{Sn}_{0.4} \mathrm{I}_{3}$ perovskite ( $\beta$ phase) into the $\mathrm{CsPb}_{0.6} \mathrm{Sn}_{0.4} \mathrm{I}_{3}$ nonperovskite $(\delta$ phase), as revealed by XRD (Supplementary Fig. 12). Such degradation is slowed down significantly in $\mathrm{G}-\mathrm{CsPb}_{0.6} \mathrm{Sn}_{0.4} \mathrm{I}_{3}$ and G-S-CsPb ${ }_{0.6} \mathrm{Sn}_{0.4} \mathrm{I}_{3}$ thin films. With the full functionalization, the latter perovskite film retains all the absorption for $2.5 \mathrm{~h}$. Figure $4 \mathrm{f}$ plots the absorbance at $800 \mathrm{~nm}$ as a function of storage time for the three thin films, where the stabilization effect of grain boundary and surface functionalization is seen clearly. In addition, the G-S-CsPb $\mathrm{Pb}_{0.6} \mathrm{Sn}_{0.4} \mathrm{I}_{3}$ thin film again shows the best thermal stability, as shown in Supplementary Fig. 13.

Device performance of $\mathrm{CsPb}_{\mathbf{0 . 6}} \mathrm{Sn}_{\mathbf{0 . 4}} \mathrm{I}_{\mathbf{3}}$ perovskites. PSC devices were fabricated to evaluate the photovoltaic performance. The inverted planar architecture of $\mathrm{FTO} / \mathrm{NiO}_{x} /$ perovskite/PCBM/
$\mathrm{BCP} / \mathrm{Ag}$ is used, which is typically used for Sn-containing PSCs ${ }^{14,35,36}$. A cross-sectional SEM image of the device is shown in Fig. 5a, where each layer is delineated clearly. Figure 5b compares typical current density-voltage $(J-V)$ responses from PSCs based on $\mathrm{N}-\mathrm{CsPb}_{0.6} \mathrm{Sn}_{0.4} \mathrm{I}_{3}, \mathrm{G}-\mathrm{CsPb}_{0.6} \mathrm{Sn}_{0.4} \mathrm{I}_{3}$, or G-S$\mathrm{CsPb}_{0.6} \mathrm{Sn}_{0.4} \mathrm{I}_{3}$ thin films. N-CsPb ${ }_{0.6} \mathrm{Sn}_{0.4} \mathrm{I}_{3}$ PSC shows relatively low PCE of $0.92 \%$ with short-circuit current density $\left(J_{\mathrm{SC}}\right), 3.47$ $\mathrm{mA} \mathrm{cm}{ }^{-2}$ and open-circuit voltage $\left(V_{\mathrm{OC}}\right)$ of $0.416 \mathrm{~V}$ and fill factor (FF) of 0.641. After grain-boundary functionalization, $J_{\mathrm{SC}}$ and $V_{\mathrm{OC}}$ are boosted to $24.07 \mathrm{~mA} \mathrm{~cm}^{-2}$ and $0.457 \mathrm{~V}$, respectively, leading to an improved PCE of 5.68\%. For the G-S-CsPb ${ }_{0.6} \mathrm{Sn}_{0.4} \mathrm{I}_{3}$ PSC, PCE of $11.28 \%$ is achieved, with $J_{\mathrm{SC}}$ of $24.57 \mathrm{~mA} \mathrm{~cm}^{-2}, V_{\mathrm{OC}}$ of $0.735 \mathrm{~V}$, and FF of 0.624 . Figure $5 \mathrm{c}$ shows the PCE statistics, indicating good reproducibility of the PCE improvement with both grain-boundary and surface functionalization. Figure $5 \mathrm{~d}$ shows $J-V$ curves of the champion PSC based on G-S$\mathrm{CsPb}_{0.6} \mathrm{Sn}_{0.4} \mathrm{I}_{3}$. This device exhibits typical hysteresis with $13.37 \%$ PCE in reverse scan and $11.39 \%$ PCE in forward scan. Maximum-power-point current/PCE output was thus monitored (Fig. 5e), which shows stabilized PCE of $12.51 \%$. Compared with high-performance low-bandgap organic-inorganic hybrid PSCs, our PSCs exhibit relatively lower FF, which may be due to more significant carrier recombination. In this regard, a systematic study about the carrier mobility and carrier diffusion lengths of

a

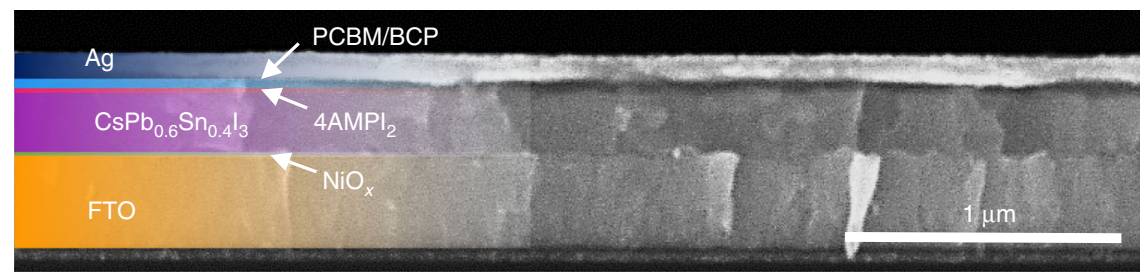

b
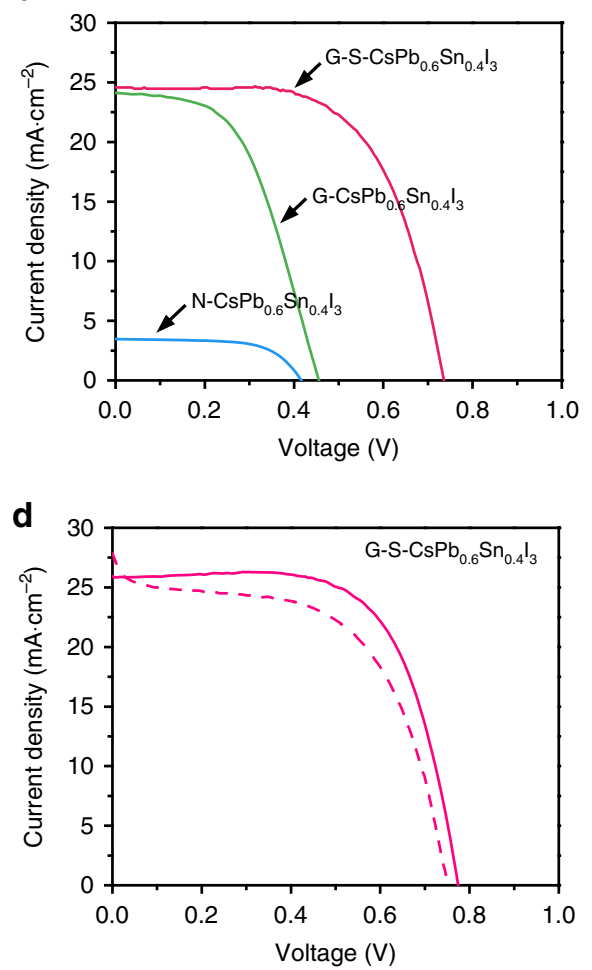

C PCE (\%)

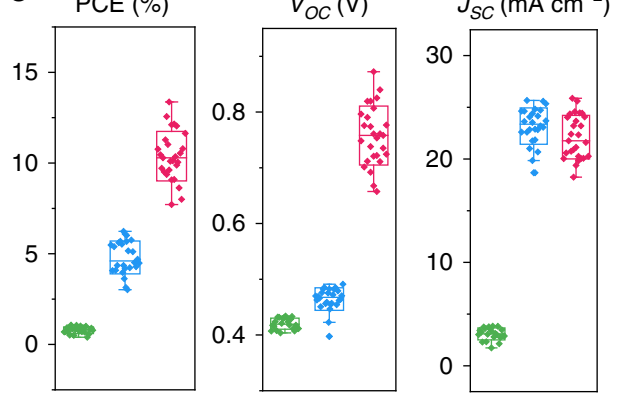

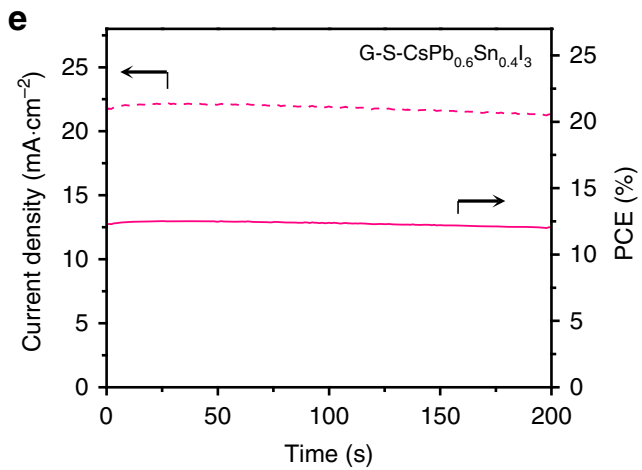

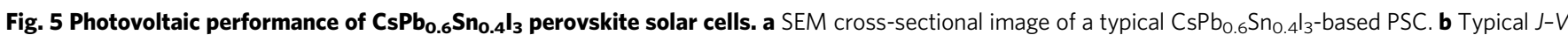
curves of perovskite solar cells based on $\mathrm{N}-\mathrm{CsPb}_{0.6} \mathrm{Sn}_{0.4} \mathrm{l}_{3}, \mathrm{G}-\mathrm{CsPb}_{0.6} \mathrm{Sn}_{0.4} \mathrm{I}_{3}$, and G-S-CsPb${ }_{0.6} \mathrm{Sn}_{0.4} \mathrm{l}_{3}$ thin films. c The corresponding J-V parameter (PCE, $V_{\mathrm{OC}}$, $J_{\mathrm{SC}}$ ) statistics of 20-30 devices based on boxplots. $\mathbf{d} J-V$ hysteresis (reverse scan: solid line; forward scan: dashed line) and e corresponding stabilized current and power outputs of the champion G-S-CsPb ${ }_{0.6} \mathrm{Sn}_{0.4} \mathrm{l}_{3}$-based PSC at maximum power point. The extracted $J-V$ parameters from b-c are shown in Table 1 . 
our films will be performed in the future for understanding and improving the carrier dynamics.

The long-term stability of the G-S-CsPb ${ }_{0.6} \mathrm{Sn}_{0.4} \mathrm{I}_{3}$-based PSCs was evaluated. First, the shelf life of the PSCs upon storage in dry $\mathrm{N}_{2}$ atmosphere at RT was tested. As shown in Fig. 6a, after 2800 $h$, no obvious PCE degradation is observed. The stability of PSCs exposed to controlled ambient conditions was also examined (Fig. 6b). Here the PSC was exposed to the ambient atmosphere (RT, below 20\% RH) for 2-3 h every 3-4 days. Interestingly, upon ambient exposure, the PCE gradually increases in the initial stage, and reaches a PCE plateau. A similar trend was observed within every cycle of ambient exposure, and eventually the overall device PCE was surprisingly increased after a total time of $1000 \mathrm{~h}$. This attests to the stability of the G-S-CsPb $\mathrm{B}_{0.6} \mathrm{Sn}_{0.4} \mathrm{I}_{3}$-based PSC for deployment in the real world where the environmental humidity usually changes in a periodic manner. Finally, the operational stability of this PSC was tested during continuous operation under one-sun illumination (nitrogen atmosphere, $\sim 45^{\circ} \mathrm{C}$ ). The conditions for such tests are chosen to be similar to those in the literature ${ }^{17,37-39}$. As seen in Fig. $6 \mathrm{c}$, after $1000 \mathrm{~h}$, the PSC shows very high PCE retention of $71 \%$. $T_{80}$ lifetime of this PSC is $653 \mathrm{~h}$, and extended stability test shows T70 lifetime of $1045 \mathrm{~h}$. It is worth noting this is the first report on 1000-h operation stability of low-bandgap PSCs. Stability test results for more devices are included in Supplementary Fig. 14 to demonstrate the reproducibility. Prior to this study, Tong et al. ${ }^{17}$ reported $220-\mathrm{h} T_{80}$ lifetime. Other related studies report only short-term or longterm shelf stability ${ }^{11,12,15,16,40}$. See Supplementary Table 2 for a detailed compilation of these stability results. The device stability during storage in the nitrogen-filled glovebox was further evaluated at a temperature of $85^{\circ} \mathrm{C}$ which is typically used in the literature $^{41}$ (Supplementary Fig. 15), which shows 77\% PCE

Table $1 \mathrm{~J}-\mathrm{V}$ parameters of $\mathrm{CsPb}_{0.6} \mathrm{Sn}_{0.4} \mathrm{I}_{3}$ perovskite solar cells.

\begin{tabular}{|c|c|c|c|c|}
\hline Sample & $J_{\mathrm{SC}}\left(\mathrm{mA} \mathrm{cm}{ }^{-2}\right)$ & $V_{\text {oc }}(\mathbf{V})$ & $\mathbf{F F}$ & PCE (\%) \\
\hline $\mathrm{N}-\mathrm{CsPb}_{0.6} \mathrm{Sn}_{0.4 \mathrm{l}_{3}}$ & $3.47 \pm 0.36$ & $0.416 \pm 0.018$ & $0.641 \pm 0.017$ & $0.92 \pm 0.14$ \\
\hline G-CsPb $0.6 \mathrm{Sn}_{0.4} \mathrm{l}_{3}$ & $24.07 \pm 1.60$ & $0.457 \pm 0.034$ & $0.517 \pm 0.052$ & $5.68 \pm 0.55$ \\
\hline G-S-CsPb $0.6 \mathrm{Sn}_{0.4} \mathrm{I}_{3}$ & $24.57 \pm 1.30$ & $0.735 \pm 0.137$ & $0.624 \pm 0.064$ & $11.28 \pm 2.09$ \\
\hline G-S-CsPb $\left.{ }_{0.6} \mathrm{Sn}_{0.4}\right|_{3}(\mathrm{R})^{\mathrm{a}}$ & 25.87 & 0.774 & 0.667 & 13.37 \\
\hline G-S-CsPb ${ }_{0.6} \mathrm{Sn}_{0.4} \mathrm{I}_{3}(\mathrm{~F})^{\mathrm{a}}$ & 26.11 & 0.749 & 0.583 & 11.39 \\
\hline
\end{tabular}
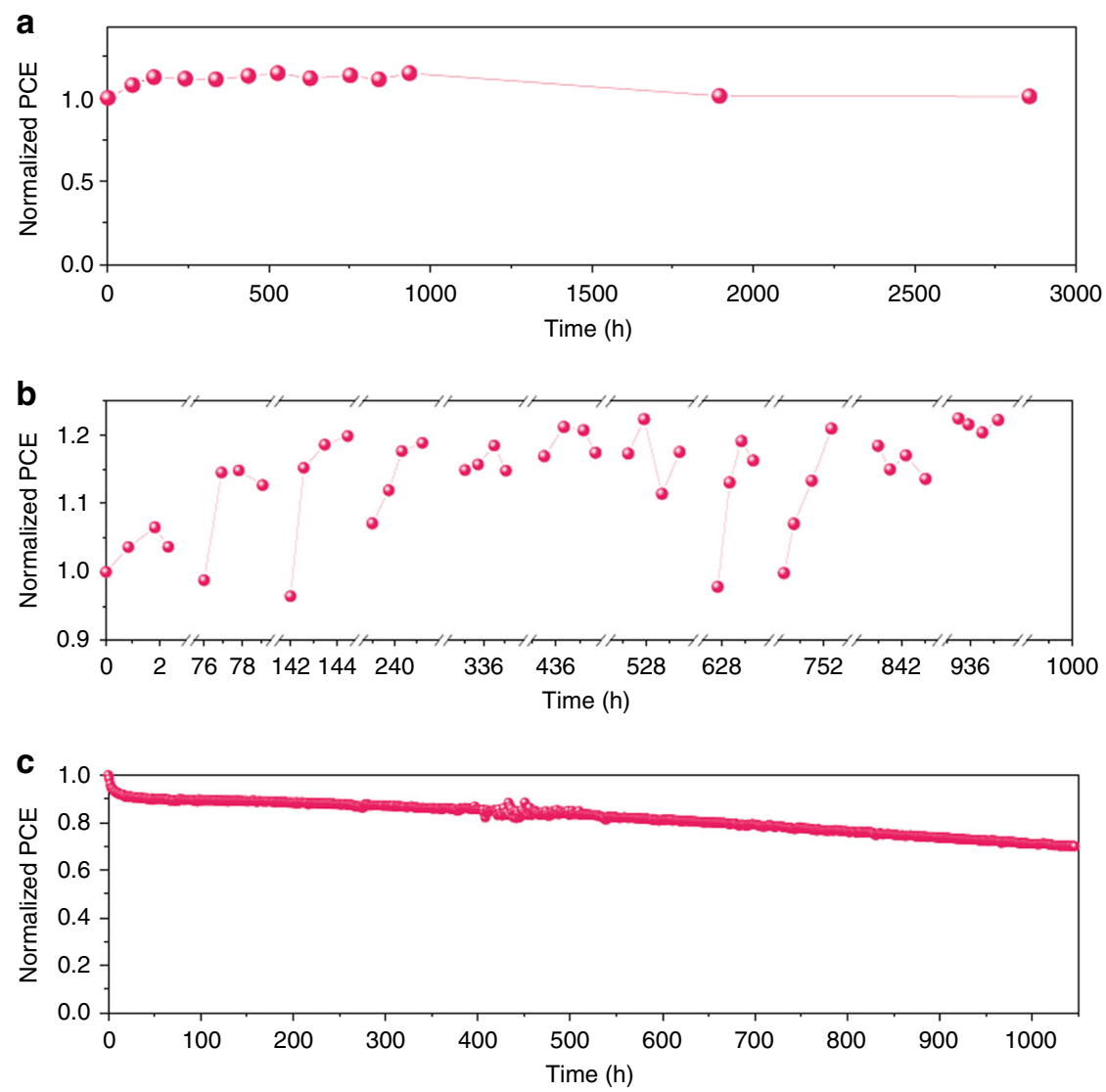

Fig. $\mathbf{6}$ Long-term stability of $\mathbf{C} \mathbf{s} \mathbf{P b}_{\mathbf{0 . 6}} \mathbf{S n}_{\mathbf{0 . 4}} \mathbf{I}_{\mathbf{3}}$ perovskite solar cells. Normalized PCE of a G-S-CsPb${ }_{0.6} \mathrm{Sn}_{0.4} I_{3}$-based PSC (unencapsulated) as a function of time under different conditions: a shelf storage in dry $\mathrm{N}_{2}$ atmosphere at RT, b controlled exposure to dry ambient environment (RT, below 20\% RH) periodically, and c continuous operation under one-sun intensity illumination (nitrogen atmosphere at around $45^{\circ} \mathrm{C}$ ). 
retention after $100 \mathrm{~h}$. In this context, this study reports lowbandgap PSCs with the most comprehensive stability results and especially the best operational stability so far. This demonstrates clearly the merit of the inorganic low-bandgap PSCs over their hybrid organic-inorganic counterparts.

\section{Discussion}

All the above results confirm $\mathrm{CsPb}_{0.6} \mathrm{Sn}_{0.4} \mathrm{I}_{3}$ as a promising lowbandgap halide perovskite candidate for PSCs. The interfaces (grain boundaries and surfaces) in this perovskite play a key role in determining its physical properties, chemical stability, and device function. With rational functionalization of the interfaces, inorganic $\mathrm{CsPb}_{0.6} \mathrm{Sn}_{0.4} \mathrm{I}_{3}$ perovskite can deliver high PCE in PSCs, on a par with those reported for hybrid organic-inorganic lowbandgap perovskites. Regarding the stability, the all-inorganic nature of $\mathrm{CsPb}_{0.6} \mathrm{Sn}_{0.4} \mathrm{I}_{3}$ perovskite offers inherently superior stability compared to their hybrid counterparts. In addition, the formation energy of Sn-defects in inorganic perovskites is smaller than that in hybrid perovskites due to the smaller ionic size of $\mathrm{Cs}^{+}$, and, thus, stronger antibonding of Sn $5 s$ with I $5 p^{42}$. All these factors contribute to the superior long-term stability that is observed under various accelerated test conditions.

While this work provides a successful demonstration of efficient inorganic low-bandgap PSCs, the detailed mechanisms underlying the key interface functionalization remain unclear, which will require further investigation. Three major effects of interface functionalization may be at play: (i) $\mathrm{SnF}_{2}$ nanophases derived from $\mathrm{SnF}_{2} \bullet 3 \mathrm{FACl}$ serve as $\mathrm{Sn}$ (II) sources for in situ annihilation of Sn-related defects generated during processing, storage, and operation of PSCs. (ii) The surface functionalization with $(4 \mathrm{AMP})^{2+}$ molecule cations may passivate the defects and prevent the bulk $\mathrm{CsPb}_{0.6} \mathrm{Sn}_{0.4} \mathrm{I}_{3}$ perovskite thin films from moisture ingression. We find the combination of $-\mathrm{NH}_{3}{ }^{+}$and $=\mathrm{NH}_{2}{ }^{+}$ functional groups may be key to the effective surface functionalization, as the replacement of (4AMP) $\mathrm{I}_{2}$ with either piperazine (with two $=\mathrm{NH}_{2}{ }^{+}$groups) iodide or phenylethylammonium (with only $-\mathrm{NH}_{3}{ }^{+}$) iodide leads to lower PCE (see $J-V$ curves in Supplementary Fig. 16). The atomistic origin of the (4AMP) $\mathrm{I}_{2}$ passivation effect needs to be studied further, which may guide the design of even more effective surface functionalization agents. (iii) The (4AMP) I $I_{2}$ surface functionalization also contributes to the change of energy level which facilitates the carrier injection at the perovskite/electron-transporting-layer interface (see UPS analyses in Supplementary Fig. 17). This is typical for interface engineering strategy in $\mathrm{PSCs}^{41,43}$. We have also observed that both G$\mathrm{CsPb}_{0.6} \mathrm{Sn}_{0.4} \mathrm{I}_{3}$ and G-S-CsPb $\mathrm{Cb}_{0.6} \mathrm{Sn}_{0.4} \mathrm{I}_{3}$ thin films still show rapid oxidation of $\mathrm{Sn}^{2+}$ to $\mathrm{Sn}^{4+}$ in the ambient environment based on preliminary XPS results (Supplementary Fig. 18). Therefore, we envision that a functionalizing molecular agent that can be more resistant to oxygen may contribute to more efficient and stable $\mathrm{CsPb}_{0.6} \mathrm{Sn}_{0.4} \mathrm{I}_{3}$-based PSC devices.

In addition, we have observed a promising, but unusual, feature of device PCE enhancement under controlled, periodic exposure to the ambient air, which may be related to further passivation of various interfaces (charge-transport-layer/perovskite interfaces, grain boundaries) induced by ambient air. This indicates that by tailoring the atmosphere-perovskite or atmosphere-device interactions, the device PCE and stability may be further enhanced. It is recognized that it will be important for evaluating the stability of the reported low-bandgap PSC devices under standardized testing conditions that are just being established ${ }^{44}$.

Based on all our results, we envision the low-bandgap inorganic perovskite of $\mathrm{CsPb}_{0.6} \mathrm{Sn}_{0.4} \mathrm{I}_{3}$ and its functionalization reported in this study pointing to a research direction for developing stable PSCs with PCEs approaching the S-Q limit.
These results may also have implications on the development of $\mathrm{Sn}$-based $\mathrm{Pb}$-free PSCs, as well as perovskite-perovskite tandem photovoltaics.

\section{Methods}

Raw chemicals. Dimethylformamide (DMF), dimethyl sulfoxide (DMSO), chlorobenzene (CBE), isopropanol (IPA), 4-(aminomethyl)piperdine (4AMP), hydroiodic acid ( $\mathrm{HI} ; 57 \mathrm{wt} \%$ in $\left.\mathrm{H}_{2} \mathrm{O}\right)$, tin(II) iodide $\left(\mathrm{SnI}_{2}\right)$, tin(II) fluoride $\left(\mathrm{SnF}_{2}\right)$, nickel (II) acetate tetrahydrate $\left(\mathrm{Ni}\left(\mathrm{COOCH}_{3}\right)_{2} \cdot 4 \mathrm{H}_{2} \mathrm{O}\right)$, and copper(II) acetate monohydrate $\left(\mathrm{Cu}\left(\mathrm{COOCH}_{3}\right)_{2} \cdot \mathrm{H}_{2} \mathrm{O}\right)$ were purchased from Sigma-Aldrich (USA). Cesium iodide (CsI) and lead iodide $\left(\mathrm{PbI}_{2}\right)$ were purchased from Alfa-Aesar (USA). Formamidinium chloride (FACl) was purchased from GreatCell Solar (Australia). Phenyl-C61-butyric acid methyl ester (PCBM) and bathocuproine (BCP) were purchased from 1-Material (Canada). All raw chemicals were used without further purification.

Preparation of precursors and thin films. (4AMP) $\mathrm{I}_{2}$ and ' $\mathrm{HPbI}_{3}$ ' solids were synthesized according to methods reported in the literature ${ }^{45,46}$. For (4AMP) $\mathrm{I}_{2}$, $2.0 \mathrm{~g}$ of $4 \mathrm{AMP}$ was added in $20 \mathrm{~mL}$ of 2 -propanol. While stirring, $7.5 \mathrm{~g}$ of $\mathrm{HI}$ was added. The solution was further stirred overnight at RT, which was followed by the removal of the solvent using a rotary evaporator. The resulting (4AMP) $\mathrm{I}_{2}$ powder was stored in glovebox for further use. For ' $\mathrm{HPbI}_{3},{ }^{\prime} 0.461 \mathrm{~g}$ of $\mathrm{PbI}_{2}$ and $0.224 \mathrm{~g}$ of $\mathrm{HI}$ were added to $0.787 \mathrm{~g}$ of DMF solvent to form a $40 \mathrm{wt} \%$ ' $\mathrm{HPbI}_{3}$ ' solution. The ' $\mathrm{HPbI}_{3}$ ' solution was heated at $80^{\circ} \mathrm{C}$ in $\mathrm{CBE}$ vapor environment overnight. During this heat treatment, the $\mathrm{CBE}$ molecules diffuse into the ' $\mathrm{HPbI}_{3}$ '/DMF solution and reduce the solubility of ' $\mathrm{HPbI}_{3}$ '. Light-yellow needle-like ' $\mathrm{HPbI}_{3}$ ' powder particles were formed and then collected. Finally, the ' $\mathrm{HPbI}_{3}$ ' crystals were dried at RT for $48 \mathrm{~h}$ under vacuum. Note that the exact composition of ' $\mathrm{HPbI}_{3}$ ' is still under debate, and the effect of ' $\mathrm{HPbI}_{3}$ ' use on the final perovskite composition remains unclear ${ }^{28,47}$. In this study, the use of ' $\mathrm{HPbI}_{3}$ ' significantly enhances the overall inorganic perovskite stability, without influencing the bandgap and crystalstructure parameters. For synthesizing $\mathrm{SnF}_{2} \bullet 3 \mathrm{FACl}$, the method reported in our previous work was used ${ }^{11}$. Briefly, $\mathrm{SnF}_{2}$ and $\mathrm{FACl}$ powders are co-dissolved in DMF in molar ratio 1:3, followed by recrystallization and harvesting of this compound.

For making $\mathrm{NiO}_{x}$ precursor solution, $125 \mathrm{mg}$ of $\mathrm{Ni}\left(\mathrm{COOCH}_{3}\right)_{2} \cdot 4 \mathrm{H}_{2} \mathrm{O}$ was dissolved in $5 \mathrm{~mL}$ of ethanol with $30 \mu \mathrm{L}$ of ethanolamine, and $20 \mathrm{mg}$ of $\mathrm{Cu}$ $\left(\mathrm{COOCH}_{3}\right)_{2} \cdot \mathrm{H}_{2} \mathrm{O}$ dissolved in $1 \mathrm{~mL}$ of ethanol. Both solutions were then stirred on hotplate at $50{ }^{\circ} \mathrm{C}$ for $30 \mathrm{~min}$. The final $\mathrm{NiO}_{x}$ precursor solution was obtained by mixing $26.5 \mu \mathrm{L}$ of copper-salt solution and $5 \mathrm{~mL}$ of nickel-salt solution. For making (4AMP) $\mathrm{I}_{2}$ solutions, a saturated (4AMP) $\mathrm{I}_{2}$ IPA solution was first prepared, which was then diluted fivefold.

For preparing $\mathrm{N}-\mathrm{CsPb}_{0.6} \mathrm{Sn}_{0.4} \mathrm{I}_{3}$ thin films, typically, a $0.7 \mathrm{M} \mathrm{N}-\mathrm{CsPb}_{0.6} \mathrm{Sn}_{0.4} \mathrm{I}_{3}$ solution was first prepared. Here, $0.1091 \mathrm{~g}$ of CsI, $0.0581 \mathrm{~g}$ of $\mathrm{PbI}_{2}, 0.0799 \mathrm{~g}$ of ' $\mathrm{HPbI}_{3}$ ', and $0.0625 \mathrm{~g}$ of $\mathrm{SnI}_{2}$ were co-dissolved in a mixed solvent of $71 \mu \mathrm{L}$ of DMSO and $500 \mathrm{mg}$ of DMF. The N-CsPb $\mathrm{B}_{0.6} \mathrm{Sn}_{0.4} \mathrm{I}_{3}$ thin films were prepared by spin-coating the solution at $3000 \mathrm{rpm}$ for $30 \mathrm{~s}$. The as-spun thin films were heated at $60{ }^{\circ} \mathrm{C}$ for $2 \mathrm{~min}$, and then $120^{\circ} \mathrm{C}$ for $30 \mathrm{~min}$. For the preparation of G$\mathrm{CsPb}_{0.6} \mathrm{Sn}_{0.4} \mathrm{I}_{3}$ thin films, $8.4 \mathrm{mg}$ of $\mathrm{SnF}_{2} \bullet 3 \mathrm{FACl}$ was added in the $0.7 \mathrm{M} \mathrm{N}$ $\mathrm{CsPb}_{0.6} \mathrm{Sn}_{0.4} \mathrm{I}_{3}$ solution to form the precursor solution. The same spin-coating and annealing conditions were used for preparing $\mathrm{N}-\mathrm{CsPb}_{0.6} \mathrm{Sn}_{0.4} \mathrm{I}_{3}$ thin films. For making G-S-CsPb $\mathrm{Pb}_{0.6} \mathrm{Sn}_{0.4} \mathrm{I}_{3}$ thin films, a post-treatment step was used, which involved the spin-coating of the (4AMP) $\mathrm{I}_{2}$ solution at $2000 \mathrm{rpm}$ for $30 \mathrm{~s}$.

Materials characterization. Laboratory XRD was performed using a highresolution diffractometer (D8 Advance, Bruker; Germany) with $\mathrm{Cu} \mathrm{K}_{\alpha}$ radiation. XRD pattern and crystal-structure information was refined using the Rietveld method with MAUD software ${ }^{48}$. The sig and $R_{\mathrm{wp}}$ parameters were found to be 1.60 and 5.44, respectively. UV-vis spectra were obtained using a spectrophotometer (UV-2600, Shimadzu; Japan). The microstructures of the thin films were observed using a scanning electron microscope (Thermo Scientific Quattro S ESEM; USA). XPS and UPS systems (5600, PHI; USA) were used to acquire the XPS and UPS spectra. The instrument utilized a monochromated $\mathrm{Al} \mathrm{K}_{\alpha}$ source for X-ray radiation at $1486.7 \mathrm{eV}$, and a UVS 40A2 (PREVAC, Poland) UV source and UV40A power supply provided by He $1 \alpha$ for UPS at $21.22 \mathrm{eV}$. Femtosecond TA measurements were performed with a $800-\mathrm{nm}, 35$-fs amplified Ti:sapphire laser at a repetition rate of $2 \mathrm{kHz}$. An optical parametric amplifier was used to produce the pump pulses with tunable wavelengths, which were reduced in repetition rate down to $1 \mathrm{kHz}$ with a mechanical chopper. A portion of the amplifier output was directed onto a 12 -mm-thick YAG crystal to produce broadband near-infrared probe pulses at $2 \mathrm{kHz}$. FTIR spectra were obtained on a spectrometer (4100, Jasco Instruments, USA). The samples for the FTIR measurements were prepared by scratching the thin films from the substrates. For time-resolved photoluminescence (TRPL) measurements, the samples were excited at $405 \mathrm{~nm}$ with a picosecond diode laser, and the emitted photons were captured using time-correlated single-photoncounting electronics (PicoQuant; Germany). Time-integrated photoluminescence spectra were excited at $405 \mathrm{~nm}$ also and measured with a CCD camera. Synchrotron-based X-ray ptychography was performed at the Velociprobe ${ }^{49}$ located at 2-ID-D beamline at the Advanced Photon Source (APS) in Argonne 
National Laboratory. An $8.8-\mathrm{keV}$ monochromatic X-ray beam was focused by a Fresnel zone plate with an outer zone width of $50 \mathrm{~nm}$. The sample was placed around $500 \mu \mathrm{m}$ downstream of the focusing position of the zone plate, with an illumination size of about $1.2 \mu \mathrm{m}$. As the sample was raster-fly scanned, a Dectris Eiger $500 \mathrm{~K}$ hybrid pixel array detector $(1.92 \mathrm{~m}$ downstream of the sample) collected forward scattering patterns at a continuous frame rate of $100 \mathrm{~Hz}$. Those scattering patterns were reconstructed into real-space images with $14 \mathrm{~nm}$ pixels by a GPU-based code ${ }^{50}$.

DFT calculation. DFT-based first-principles calculations were conducted using the plane-wave basis in Cambridge Sequential Total Energy Package (CASTEP) ${ }^{51}$ code. The exchange-correlation functional was used by Perdew-Burke-Ernzerhof generalized gradient approximation (PBE-GGA) ${ }^{52}$. The ultrasoft pesudopotentials ${ }^{53}$ within the frozen core approximation were employed, i.e., Cs $5 \mathrm{~s}^{2} 5 \mathrm{p}^{6} 6 \mathrm{~s}^{1}, \mathrm{~Pb} 5 \mathrm{~d}^{10}$ $6 s^{2} 6 p^{2}$, Sn $5 s^{2} 5 p^{2}$, and I $5 s^{2} 5 p^{5}$. The Monkhorst-Pack type $k$-point was $3 \times 3 \times 2$. The kinetic energy cutoff was set to $290 \mathrm{eV}$. The geometry optimization thresholds for energy change, maximum force, maximum stress, and maximum displacement between cycles were set to $5 \times 10^{-6} \mathrm{eV}$ atom $^{-1}, 0.01 \mathrm{eV}^{-1}, 0.02 \mathrm{GPa}$, and $5 \times$ $10^{-4} \AA$, respectively.

Device fabrication. Fluorinated-tin oxide (FTO)-coated glass substrates were cleaned by sequentially washing with detergent, deionized water, ethanol, acetone, and IPA. Before use, the FTO-glass substrates were treated with UV-ozone for $20 \mathrm{~min}$. Subsequently, a $\mathrm{NiO}_{x}$ compact layer was deposited by spin-coating the precursor solution at $3000 \mathrm{rpm}$ for $60 \mathrm{~s}$, followed by annealing at $400{ }^{\circ} \mathrm{C}$ for $60 \mathrm{~min}$ in air. Next, the perovskite thin film was deposited according to the procedure described above. PCBM (using a solution of $23 \mathrm{mg} \mathrm{mL}^{-1}$ in CBE) and BCP (a saturated solution in IPA) were then sequentially spin-coated onto the perovskite thin films at $3000 \mathrm{rpm}$ for $30 \mathrm{~s}$ and $1500 \mathrm{rpm}$ for $30 \mathrm{~s}$, respectively. Finally, 100-nm Ag layer was thermally evaporated with a shadow mask. Except the steps of FTO-glass cleaning and $\mathrm{NiO}_{x}$ deposition, all device fabrication steps were conducted in a $\mathrm{N}_{2}$-filled glovebox with both $\mathrm{O}_{2}$ and $\mathrm{H}_{2} \mathrm{O}$ levels below $0.1 \mathrm{ppm}$.

Solar cell performance testing. The $J-V$ characteristics of PSCs were measured using the 2400 SourceMeter under simulated one-sun AM1.5G $100 \mathrm{~mW} \mathrm{~cm}^{-2}$ intensity (Sol3A Class AAA, Oriel, Newport, USA) in air (RT, 40 to $60 \% \mathrm{RH}$ ) using both reverse (from $V_{\mathrm{OC}}$ to $J_{\mathrm{SC}}$ ) and forward (from $J_{\mathrm{SC}}$ to $V_{\mathrm{OC}}$ ) scans with a step size of $0.0056 \mathrm{~V}$ and a delay time of $10 \mathrm{~ms}$. The maximum-power output stability of PSCs was measured by monitoring the J output at the maximum powerpoint bias (deduced from the reverse-scan $J-V$ curves) using the 2400 SourceMeter. A typical active area of $0.105 \mathrm{~cm}^{2}$ was defined using a non-reflective mask for the $J-$ $V$ measurements. The stable PCE output was calculated using the following relation at the maximum power point: $\mathrm{PCE}(\%)=J\left(\mathrm{~mA} \mathrm{~cm}^{-2}\right) \times V(\mathrm{~V})$. A shutter was used to control the one-sun illumination on the PSC.

Long-term stability testing. For device operational stability test, unencapsulated PSCs were placed in a sealed cell holder with a transparent quartz cover. A continuous flow of $\mathrm{N}_{2}$ gas was passed through the holder to minimize the water and oxygen content in the atmosphere. $J-V$ curves were measured every $12 \mathrm{~h}$. The temperature of the devices was maintained at around $45^{\circ} \mathrm{C}$ under continuous onesun-intensity white-LED illumination. Between the $J-V$ measurements, the PSCs were biased at the maximum-power-point voltage using a potentiostat under illumination. For device shelf stability tests, PSCs were repeatedly measured under standard testing conditions after certain durations of storage in nitrogen or air, which is described in detail in the main text.

Reporting summary. Further information on research design is available in the Nature Research Reporting Summary linked to this article.

\section{Data availability}

The authors declare that the data related to this study are available upon reasonable request.

Received: 2 September 2019; Accepted: 5 December 2019; Published online: 09 January 2020

\section{References}

1. Dunlap-Shohl, W. A., Zhou, Y., Padture, N. P. \& Mitzi, D. B. Synthetic approaches for halide perovskite thin films. Chem. Rev. 119, 3193-3295 (2019).

2. NREL. Best research-cell efficiency chart. https://www.nrel.gov/pv/cellefficiency.html. Accessed 6 Nov 2019.
3. Snaith, H. J. Present status and future prospects of perovskite photovoltaics. Nat. Mater. 17, 372-376 (2018).

4. Wang, Y. et al. Stabilizing heterostructures of soft perovskite semiconductors Science 365, 687-691 (2019).

5. Jiang, Q. et al. Surface passivation of perovskite film for efficient solar cells. Nat. Photonics 13, 460-466 (2019).

6. Bai, S. et al. Planar perovskite solar cells with long-term stability using ionic liquid additives. Nature 571, 245-250 (2019).

7. Kojima, A., Teshima, K., Shirai, Y. \& Miyasaka, T. Organometal halide perovskites as visible-light sensitizers for photovoltaic cells. J. Am. Chem. Soc. 131, 6050-6051 (2009).

8. Zhou, Y., Game, O. S., Pang, S. \& Padture, N. P. Microstructures of organometal trihalide perovskites for solar cells: their evolution from solutions and characterization. J. Phys. Chem. Lett. 6, 4827-4839 (2015)

9. Xiao, Z., Zhou, Y., Hosono, H., Kamiya, T. \& Padture, N. P. Bandgap optimization of perovskite semiconductors for photovoltaic applications. Chem. Eur. J. 24, 2305-2316 (2018).

10. Shockley, W. \& Queisser, H. J. Detailed balance limit of efficiency of $p-n$ junction solar cells. J. Appl. Phys. 32, 510-519 (1961)

11. Zong, Y., Zhou, Z., Chen, M., Padture, N. P. \& Zhou, Y. Lewis-adduct mediated grain-boundary functionalization for efficient ideal-bandgap perovskite solar cells with superior stability. Adv. Energy Mater. 8, 1800997 (2018).

12. Zhao, D. et al. Efficient two-terminal all-perovskite tandem solar cells enabled by high-quality low-bandgap absorber layers. Nat. Energy 3, 1093-1100 (2018).

13. Zhao, D. et al. Low-bandgap mixed tin-lead iodide perovskite absorbers with long carrier lifetimes for all-perovskite tandem solar cells. Nat. Energy 2, 17018 (2017).

14. Li, C. et al. Reducing saturation-current density to realize high-efficiency lowbandgap mixed tin-lead halide perovskite solar cells. Adv. Energy Mater. 9, 1803135 (2019).

15. Yang, $\mathrm{Z}$. et al. Stable low-bandgap $\mathrm{Pb}$-Sn binary perovskites for tandem solar cells. Adv. Mater. 28, 8990-8997 (2016).

16. Ogomi, Y. et al. $\mathrm{CH}_{3} \mathrm{NH}_{3} \mathrm{Sn}_{\mathrm{x}} \mathrm{Pb}_{(1-\mathrm{x})} \mathrm{I}_{3}$ perovskite solar cells covering up to 1060 nm. J. Phys. Chem. Lett. 5, 1004-1011 (2014).

17. Tong, J. et al. Carrier lifetimes of $>1 \mu$ s in $\mathrm{Sn}-\mathrm{Pb}$ perovskites enable efficient all-perovskite tandem solar cells. Science 364, 475-479 (2019).

18. Lin, R. et al. Monolithic all-perovskite tandem solar cells with $24.8 \%$ efficiency exploiting comproportionation to suppress $\mathrm{Sn}(\mathrm{II})$ oxidation in precursor ink. Nat. Energy 4, 864-873 (2019).

19. Ju, M.-G. et al. Toward eco-friendly and stable perovskite materials for photovoltaics. Joule 2, 1231-1241 (2018).

20. Zhou, Y. \& Zhao, Y. Chemical stability and instability of inorganic halide perovskites. Energy Environ. Sci. 12, 1495-1511 (2019).

21. Wang, P. et al. Solvent-controlled growth of inorganic perovskite films in dry environment for efficient and stable solar cells. Nat. Commun. 9, 2225 (2018).

22. $\mathrm{Wu}, \mathrm{T}$. et al. Efficient and stable $\mathrm{CsPbI}_{3}$ solar cells via regulating lattice distortion with surface organic terminal groups. Adv. Mater. 31, 1900605 (2019).

23. Tai, Q., Tang, K.-C. \& Yan, F. Recent progress of inorganic perovskite solar cells. Energy Environ. Sci. 12, 2375-2405 (2019).

24. Zhou, Y. et al. Doping and alloying for improved perovskite solar cells. J. Mater. Chem. A 4, 17623-17635 (2016).

25. Ke, W., Stoumpos, C. C. \& Kanatzidis, M. G. "Unleaded” perovskites: status quo and future prospects of tin-based perovskite solar cells. Adv. Mater. 31, 1803230 (2019).

26. Filip, M. R. \& Giustino, F. The geometric blueprint of perovskites. Proc. Natl Acad. Sci. USA 115, 5397-5402 (2018).

27. Chen, M. et al. Highly stable and efficient all-inorganic lead-free perovskite solar cells with native-oxide passivation. Nat. Commun. 10, 16 (2019).

28. Wang, Y. et al. Thermodynamically stabilized $\beta-\mathrm{CsPbI}$-based perovskite solar cells with efficiencies $>18$. Science 365, 591-595 (2019).

29. Wang, Y. et al. Efficient $a-\mathrm{CsPbI}_{3}$ photovoltaics with surface terminated organic cations. Joule 2, 2065-2075 (2018).

30. Wang, F. et al. Phenylalkylamine passivation of organolead halide perovskites enabling high-efficiency and air-stable photovoltaic cells. Adv. Mater. 28, 9986-9992 (2016).

31. Schulz, P., Cahen, D. \& Kahn, A. Halide perovskites: is it all about the interfaces? Chem. Rev. 119, 3349-3417 (2019).

32. Liu, T. et al. Stable formamidinium-based perovskite solar cells via in situ grain encapsulation. Adv. Energy Mater. 8, 1800232 (2018).

33. Pfeiffer, F. X-ray ptychography. Nat. Photonics 12, 9-17 (2017)

34. Liu, Y., Zhang, N., Yu, C., Jiao, L. \& Chen, J. MnFe $\mathrm{O}_{4} @ \mathrm{C}$ nanofibers as highperformance anode for sodium-ion batteries. Nano Lett. 16, 3321-3328 (2016).

35. Wang, N. et al. Heterojunction-depleted lead-free perovskite solar cells with coarse-grained B- $\gamma$-CsSnI 3 thin films. Adv. Energy Mater. 6, 1601130 (2016). 
36. Chi, D. et al. Composition and interface engineering for efficient and thermally stable Pb-Sn mixed low-bandgap perovskite solar cells. Adv. Funct. Mater. 28, 1804603 (2018).

37. Turren-Cruz, S. H., Hagfeldt, A. \& Saliba, M. Methylammonium-free, highperformance, and stable perovskite solar cells on a planar architecture. Science 362, 449-453 (2018).

38. Tan, H. et al. Efficient and stable solution-processed planar perovskite solar cells via contact passivation. Science 355, 722-726 (2017).

39. Grancini, G. et al. One-Year stable perovskite solar cells by $2 \mathrm{D} / 3 \mathrm{D}$ interface engineering. Nat. Commun. 8, 15684 (2017).

40. Wang, C., Song, Z., Li, C., Zhao, D. \& Yan, Y. Low-bandgap mixed tin-lead perovskites and their applications in all-perovskite tandem solar cells. Adv. Funct. Mater. 29, 1808801 (2019).

41. $\mathrm{Wu}, \mathrm{S}$. et al. A chemically inert bismuth interlayer enhances long-term stability of inverted perovskite solar cells. Nat. Commun. 10, 1161 (2019).

42. Shi, T. et al. Effects of organic cations on the defect physics of tin halide perovskites. J. Mater. Chem. A 5, 15124-15129 (2017).

43. Zhang, Y. et al. Fusing nanowires into thin films: fabrication of gradedheterojunction perovskite solar cells with enhanced performance. Adv. Energy Mater. 9, 1900243 (2019).

44. Saliba, M. Perovskite solar cells must come of age. Science 359, 388-389 (2018).

45. Pang, S. et al. Transformative evolution of organolead triiodide perovskite thin films from strong room-temperature solid-gas interaction between $\mathrm{HPbI}_{3}$ $\mathrm{CH}_{3} \mathrm{NH}_{2}$ precursor pair. J. Am. Chem. Soc. 138, 750-753 (2016).

46. Chen, M. et al. Lead-free Dion-Jacobson tin halide perovskites for photovoltaics. ACS Energy Lett. 4, 276-277 (2019).

47. Ke, W., Spanopoulos, I., Stoumpos, C. C. \& Kanatzidis, M. G. Myths and reality of $\mathrm{HPbI}_{3}$ in halide perovskite solar cells. Nat. Commun. 9, 4785 (2018).

48. Lutterotti, L. Total pattern fitting for the combined size-strain-stress-texture determination in thin film diffraction. Nucl. Instrum. Methods Phys. Res. B 268, 334-340 (2010).

49. Deng, J. et al. The velociprobe: an ultrafast hard X-ray nanoprobe for highresolution ptychographic imaging. Rev. Sci. Instrum. 90, 083701 (2019).

50. Nashed, Y. S. et al. Parallel ptychographic reconstruction. Opt. Express 22, 32082-32097 (2014).

51. Segall, M. D. et al. First-principles simulation: ideas, illustrations and the CASTEP code. J. Phys. Condens. Matter 14, 2717 (2002).

52. Perdew, J. P., Burke, K. \& Ernzerhof, M. Generalized gradient approximation made simple. Phys. Rev. Lett. 77, 3865-3868 (1996).

53. Hamann, D. R. Generalized norm-conserving pseudopotentials. Phys. Rev. B 40, 2980-2987 (1989).

\section{Acknowledgements}

The work at Brown University was funded by the Office for Naval Research (Gran No. N00014-17-1-2232), and the National Science Foundation (Grant Nos. OIA1538893 and OIA-1929019). The work at Kunming University of Science and Technology was funded by National Key R\&D Program of China (Grant No.

2019YFB1503202). This research used resources of the Advanced Photon Source and Center for Nanoscale Materials, both U.S. Department of Energy (DOE) Office of Science User Facilities operated for the DOE Office of Science by Argonne National Laboratory under Contract No. DE-AC02-06CH11357. K.Z. acknowledges the support from the U.S.
DOE under Contract No. DE-AC36-08GO28308 with Alliance for Sustainable Energy, Limited Liability Company (LLC), the Manager and Operator of NREL, and the Derisking Halide Perovskite Solar Cells program of the National Center for Photovoltaics, funded by the U.S. Department of Energy, Office of Energy Efficiency and Renewable Energy, and Solar Energy Technologies Office. M.H. acknowledges the support from Chinese Scholarship Council. Experimental assistance from Dr. Q. Dong and Mr. S.K. Yadavalli is also acknowledged.

\section{Author contributions}

Yuanyuan Z. and N.P.P. conceived the idea and designed the experiment. Yuanyuan Z N.P.P. and J.F. supervised the project. M.H. performed perovskite synthesis, XRD, SEM UV-vis, device fabrication, and performance testing. M.C. assisted in the PSCs fabrication. M.H., Yunxuan Z. and X.C. performed DFT calculations. F.Q. and J.G. measured XPS spectra. H.D. P.G., and R.D.S. performed transient photoluminescence/absorption spectroscopy. H.Z., J.D., Yuanyuan Z., Y.Y. and Y.J. performed X-ray synchrotron ptychography experiments and analyzed the results. J.G. assisted in analyzing the transient spectroscopy results. Z.D. and M.C. synthesized (4AMP) $\mathrm{I}_{2}$ salts. K.Z. contributed to the discussion on device characteristics. Yuanyuan Z. and N.P.P prepared the manuscript with assistance from M.H. and contributions from all the other co-authors.

\section{Competing interests}

The authors declare no competing interests.

\section{Additional information}

Supplementary information is available for this paper at https://doi.org/10.1038/s41467019-13908-6.

Correspondence and requests for materials should be addressed to J.F., N.P.P. or Y.Z.

Peer review information Nature Communications thanks Antonio Abate, Wei Chen and the other, anonymous, reviewer(s) for their contribution to the peer review of this work.

Reprints and permission information is available at http://www.nature.com/reprints

Publisher's note Springer Nature remains neutral with regard to jurisdictional claims in published maps and institutional affiliations.

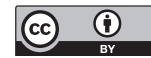

Open Access This article is licensed under a Creative Commons Attribution 4.0 International License, which permits use, sharing, adaptation, distribution and reproduction in any medium or format, as long as you give appropriate credit to the original author(s) and the source, provide a link to the Creative Commons license, and indicate if changes were made. The images or other third party material in this article are included in the article's Creative Commons license, unless indicated otherwise in a credit line to the material. If material is not included in the article's Creative Commons license and your intended use is not permitted by statutory regulation or exceeds the permitted use, you will need to obtain permission directly from the copyright holder. To view a copy of this license, visit http://creativecommons.org/ licenses/by/4.0/.

(C) The Author(s) 2020 